\title{
Active information system on the public spaces of Andalusia: Andalucía Transversal Laboratory
}

\author{
J. Sobrino ${ }^{1}$, E. Larive ${ }^{1}$, M. V. Segura ${ }^{2}$, C. Gallardo ${ }^{1}$, \\ D. Hermosilla ${ }^{1}$, J. J. Gómez ${ }^{3}$, P. Baturone ${ }^{3}$, M. D. Monsalve ${ }^{1}$ \\ \& A. López ${ }^{1}$ \\ ${ }^{1}$ University of Seville, Spain \\ ${ }^{2}$ Town Planning Department of Seville City Council, Spain \\ ${ }^{3}$ Architect's Office Lacasavacía, Spain
}

\begin{abstract}
The research project must be able to integrate the historical view and new urban and emergences, in an interactive system, with the agents who have responsibilities, interests and desires regarding the public spaces in Andalusia. The research activity is part of a paradigm shift on the public space in the last two decades, from different disciplines, public initiatives, technical documents and intervention actions that are being carried out by active research on the territory, landscape, heritage, production and their associated public spaces. Currently, the generation of data and information processes is reaching such a vast scale, that the main problems facing its management are those of standardization, integration, connectivity and access. Therefore, the main objective of the management and use of the information sources will consist of the comprehensive incorporation of the data from different public and private administrations on the public spaces of Andalusia. Our project is structured in a model register of potential public spaces that allows us to identify the what, where, how and who, in a system-network of a new Europe of cities and citizens of shared spaces. Our basic objectives are articulated through a narrative on public spaces in Andalusia which is structured from a significant, plural and representative selection of existing and potential spaces, noting their scale, position, morphology, function, conflicts, history, uses and potential.
\end{abstract}

Keywords: public space, emergent spaces, public urban policies, active methodology, geographic information systems, management of public space. 


\section{Introduction}

The public space in Andalusia has been structured throughout history by the logic and strategies common to the Mediterranean civilisations. Following Choay [1], we can distinguish a complex evolution in the city, marked by the proto-city of the founding pre-existences (place and fabric), the space of mediaeval contact (contiguity and proximity), the space of Renaissance and baroque spectacle (theatre and representative), the space of the first industrialisation (circulation and production) and the space of modernity (connection and disintegration). In the public space of our time, new proto-spaces are produced resulting from the change of civilisation, marked by the redefinition of infrastructures, the digital information control systems, complex and permanent mobility and the necessity of recovery and recycling of the obsolescent.

The historical public spaces of Andalusia constitute an extraordinary cultural heritage, the full understanding of which stems from their diachronic cultural contextualization as historical urban landscapes. These are spaces, in their urban or rural scales, into which initiatives of all kinds are inserted territorially which shape the new contemporary public spaces as a result of the various functionalities (political, territorial, economic, symbolic, cultural), all of which can be seen in complex scenarios, as a result of different processes of resignification.

\section{Research methodology}

The research is focused on the paradigm shift on the public space which, over the last two decades, has seen active research on the territory, landscape, heritage, production and their associated public spaces, using different disciplines, public initiatives, technical documents and intervention actions. This process raises an historical and critical reflection on the evolution of the public spaces in Andalusia, on their social, cultural, architectural, urban and landscaping representations and repercussions. Rediscovering the public space in Andalusia supposes intervening in the reactivation of the historical city, and asking the question: What is the nature of the new public places in Andalusia?

This project has delved into the new landscapes of living, into their conurbations and suburbs, into the new forms of sociability, into the quiescent infrastructural interstices and into the spontaneous situations. The historical view has been integrated with the new urban emergences/emergencies in an interoperable system with the agents who have responsibilities, interests or desires regarding public spaces in Andalusia.

An investigation has been undertaken into the genesis of new urban landscapes, those spontaneous and urgent emergences which do not correspond with the diachronic anthropization of the territory, but with a new unprecedented entity derived from the current forms of mobility and transport of goods, from communication, economy, energy, production and thought. These new places of sociability, of the citizenry, are submitted to strong dynamics of change. Within their environs are produced the meetings, the worrying situations, the landscapes 
of the contemporaneity in Andalusia. They have been tested with mapping systems, data diagrams, open processes, models of evolution, models of change, models of impact and models of decision. An attempt has been made to identify the indicators of creation, qualification, transformation and destruction of these urban landscapes: their morphology, demography, history, technology, dynamics of development, mobility trends and systems of relations. Our project is really an open model for registering possible public spaces which allows us to identify the what, where, how and who, in a system-network/Internet system that commits to a new Europe of cities and citizens of shared spaces.

Defining the public spaces of Andalusia is not an easy task, due to the extensive history of this region, to its geographical diversity, the multi-scalarity of its settlements, its cultural diversity and its deep and intense urbanization. We were faced with thousands of public spaces for characterisation, all of them important and interesting. The majority are core components of urban life, whether central or suburban. Others will be of an interstitial or articulating character, being located between population centres that are no great distance from each other, as connectors or spatial infrastructures in which to reflect, to look, to exchange or to use. In addition, the invisible places, the isolated public spaces, reserved, privatised, hidden, obsolete or inhibited, in perfect quiescence and in complete separation from the citizenry.

Innumerable public spaces which, sharing the terms "space" and "public", endow Andalusia with countless different and individual histories, differences that have to do with the local and the global, with the formally morphological and with the social experience. In all those spaces we also found the architecture of the public space, understood as an idea, project, transformation and appropriation of the place, whether spontaneously or planned.

Currently, the generation of data and information processes is reaching such an extensive scale that the main problems found in their management are those of standardisation, integration, connectivity and access. For that reason, the main objective of the management and use of the sources of information consist of the comprehensive incorporation of the information originating from different public administrations and agents on the public spaces of Andalusia.

Our project sets out a model of registering possible public spaces, which will allow us to identify the what, where, how and who, in a network system of the new Europe of cities and citizens of shared spaces. The operational analysis approaches the levels of production, colonization, development, transformation, attraction and destruction of these spaces, and produces a cartography of reference data necessary to activate a new strategic process.

The first hypothesis of the research is the trans-scalar test. The scalar mobility of the sample enriches the starting situation and allows the project or the action to be woven with more complex results of greater scope. The geographic information systems are instruments that have allowed this multiplicity of spatial relationships and a vast accumulation and superimposition of data to be established. The second hypothesis is the transversality. The samples present a system of fragmented and conflicting competences: infrastructures, mobility, management, project, participation, governance. Therefore, they are systems that lose the capacity to 
operate in an integrated manner. The third hypothesis is the trans-disciplinarity. This manner of understanding the public space forces a reorientation of the different professional disciplines to give a more effective response to the scalar diversity and spatial transversality. It is necessary to strengthen the disciplinary fields and induce alternative professional practices, which flow between the project, the management, the political decision and programmatic definitions in the long term. The fourth hypothesis is the transference. The project receives feedback from its activities in transit, experiments of awareness, formation and activation on the public space in Andalusia. We try to be in contact with the citizenry and intervening agents.

The methodology used is in open code, transdisciplinary and more global than purely urbanistic or architectural. The model used is experimental, integrating, focused on the user and transverse in character. For this, an information system was designed for the analysis of visible and nonvisible data, a system where the variables that affect the territory can be represented spatially in the place in which they occur. The mapping of these values and their transverse relationships reveal those nonvisible data that are key in the research. The experiment has allowed the superimposition and analysis of all the available georeferenced information, in a process of continuous update, with the philosophy of open code.

Using spatial analysis tools and platforms of participation we will give voice to all the agents and will attempt to make the results of the project visible by immediate transfer. The toolbox with which the research process has been furnished is composed of three sets of applications: active communication, data container and a geographic information system (GIS).

\section{Theoretical and methodological approaches on the public space}

Starting from the multidimensionality, as Staeheli describes this concept [2] of the idea, as theoretical (philosophical, sociological, anthropological, environmental and urban), operational (geographic, cultural, architectural, ecological and political) and symbolic (perceptive, creative, appropriative, interactive and socialising), of the public space, it is difficult to establish a reliable, updated and concise state of the question that includes the approaches and epistemological and methodological trends on the burning question of the public space in current society. For this, we will limit some of its variables to the conceptual sphere that constitutes the operational core of our research project "Active information systems of the public spaces in Andalusia: the Emergent Spaces and the Spaces in Emergency". Emergence can be defined as the action and effect of emerging, to appear, to surface; and Emergency as that situation of danger or disaster that requires an immediate action.

These processes allow us to incorporate the new occurrence itself (meaning 1), which did not exist or was hidden, as public space, as the result of unforeseen changes, in the spheres of the urban, the architectural, the cultural, the social or the economic, informal and nomadic, and formal and stable in character. Also, to incorporate the public space that arises from a demand of groups or collectives 
(meaning 2), as an urgent response to needs long demanded by the social sphere. The public spaces defined by these meanings form an emergent part of the city or the territory, where ruptures are being produced with previous models of ordinance, signification or formalisation of the social production of the space. Therefore, we have established three experimental viewpoints.

The first viewpoint includes the concept of "public", as that sphere of living composed and formalised by the space where the freedom of circulation of ideas, people, merchandise and services takes place. The second viewpoint refers to "participation", as the sphere in which the interaction between possession and use takes place. The third viewpoint refers to the sphere of its interpretation which, although composed of extraordinary subjectivity, allows the objectification of the actors: social, institutional and professional. These three viewpoints transversally relate the constituent parameters of the public space, such as its tangible character and its immateriality.

\section{The space of what is public in Andalusia and what is public about the space}

The public space is the ideal territory for the exercise of rights, it has always been so. Rights were born of the policy, of the concept of what is public, as opinion or as presence, from ancient Athens, in its agora, to the 15M Movement, in the Puerta del Sol. However, paradoxically, rights have also been repressed in the public spaces, from the slaughter in the Plaza de las Tres Culturas of Tlatelolco in October 1968, to the Tiananmen Square protests of June 1989. The public space territorialises opinion and protest, becoming an historical scenario in which the conflicts between public and private, between control and participation, can be visualised. The public space is a humanised territory, reinterpreting Miguel Fisac, as a physical + ecological + climatic + psychological + aesthetic + spiritual environment: that is to say, as a human ecosystem.

Today the public space forms part of the rights of the citizen. It is not simply the urban surroundings of what is built, but is the original core around which urban life revolves. However, it is a badly managed and unequally distributed right. The right between centre and suburb, between metropolis and villa, between residence and work, between owners and dispossessed, between machines and people, between genders and ages, between leisure and business. So, when we speak of rights, of the right to the public space, it is necessary to remember the legislative limitations, which remain intact in the present political programmes and in the permanent social demands, when we recognise exclusively the right to housing, as a space of Fordist life and not the right to comprehensive living, to the humanised territory, to the city, in its bio-social-diverse dimension. The right to the city, the city in which we live, work, study, celebrate, have fun, trade, move and recognise ourselves as free citizens.

The policies on the public space in the Andalusian territory must include this dimension of the public space as a place of liaison, of connection, of representation and of socialization. Today, in the digital era, the public space must be recognised as a fundamental eco-social-system for the life of the citizens, and must generate 
lines of action and investment that re-balance the socio-territorial inequalities, which correct the effects of the speculative land market, which return the social centrality to the meeting places, which reconcile the city of the past with the city of the present and which design places from humanised architecture.

Our research project on emergent spaces in Andalusia focused on detecting and understanding the concepts of emergence: as the new, the nascent, the embryonic and the transverse, and, of emergency: as the urgent, the claiming, the necessary and the balancing.

What factors must we focus on to be able to compose this multiform picture of the Andalusian public space? Which must be the variables in which we must interest ourselves to know its origin, its life-cycle and its present maintenance? Why do the public spaces appear in a specific place, and which is its internal logic? Why do some public spaces reappear and revitalise, while others decline and are abandoned? Which are the keys of the success of the public spaces: their history, their design, their morphology, their construction, their equipment or their uses? Or perhaps, the luck of those spaces lies in its users, its carers, as they say in the Casa del Pumarejo? This is to say, is the physical dimension or the social organisation of the space more important?

In the public space we can distinguish, with Lefevbrian clarity [3], how the city is organised, how the fight for the space comes about, which are the conflicts that are produced and reproduced there, as well as their institutional origin and the malaise that they generate. When thinking about the public space in Andalusia today, we continue to be faced with a crucial question that affects all the spheres of the Techno-Global Era: The people or the objects?

Therefore, which are the keys of the success of the institutional programmes of creation or maintenance of the public spaces: the emotions or the equipment? The space, as a symbolic centrality, or its borders of sociability? Only the space as such, or also its connections? The space in one day or any day, any month, any hour, any place? The history of the cities in which they are found, or the life of the people who inhabit them?

\section{Public space as a history of the community}

We start from the definition established by UNESCO [4] on the Historical Urban Landscape as an expression of the cultural diversity resulting from the permanent and continuous process of the historical stratification that is tangibly observed in the city, and which, at the same time, is related to the symbolic values and the intangible assets through the sensorial perception, producing a degree of knowledge and study characterised by the interconnections between these two levels.

We share with Foucault [5] the way in which we understand the history of the community, not only in its macro-political dimension defined by the institutionally dominant, but also in its micro-political dimension defined by the effect of its coercive normalisation. We speak, therefore, of the process of construction of history as a story of the power associated with the space as a representation of its narration, in a task directed to the "manufacture" of the history of the nation as 


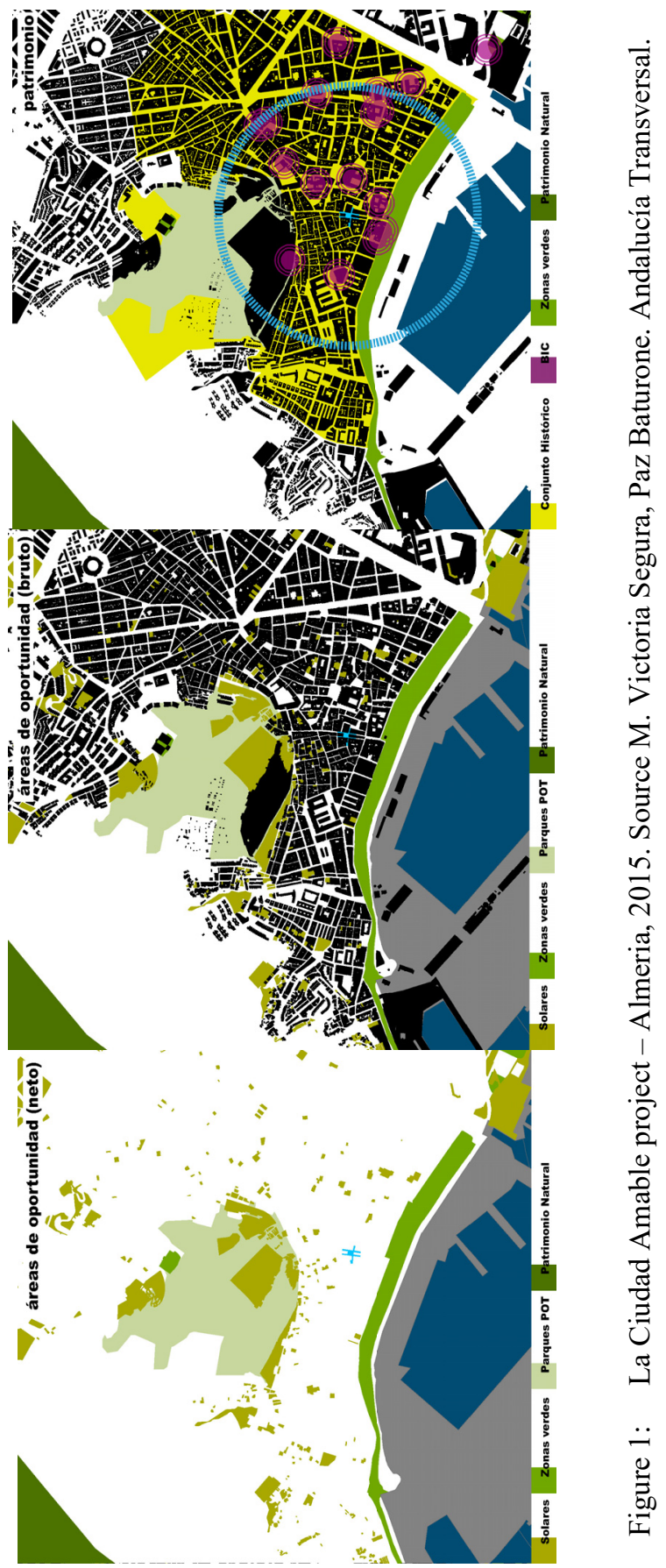


opposed to the history of the people [6], those histories that happen in "the outside" and which shape an amalgam of stories in which orthodoxy and heterotopia intermingle.

Although it is necessary to emphasise that the definition of public space has to be associated for our time with the establishment of the political model of parliamentary democracy and with the shaping of "public opinion" as an expression of the desires, dissatisfactions, demands and, also, manipulations, of the citizenry as a classless structure, thanks to the freedom of the press, to the foundation of the media and to the development of communication technologies. One of the most burning, and most suggestive, conflicts of our present is that of the free access to the means of communication, both public and private, by the citizens, as a form of significant expression of the plurality of the social body, a situation detected by the American politician and philosopher, Lippman [7], and which, evidently, we can translate to the idea of the public space as a place of communication, and to the present difficulties for its free expression. At the present time, phenomena such as the $15 \mathrm{M}$ Movement in the Puerta del Sol or the Occupy Wall Street Movement, lay out with decisive sharpness the conflict between official democracy and direct democracy, taking the public space as the agora for the staging of this powerful contradiction.

A second dimension of what is public is its history. And, although it is evident, for the case of Andalusia and also for other regions with sufficient historical density, that the public space plays a central role in the Historical Centres, the public space as cultural heritage is already structured as a system of articulating spaces of the cultural assets or as the specific context of each specific asset, of its surroundings, of its viewshed, in its global spatial perception. This is to say, as García affirms [8], as a cultural space in its deep historical sense.

However, all this, without losing the historical perspective of how the construction of the public space took place in the European cities, especially from the 18th century, when, as indicated by Sennett [9], it would be generating a control, increasingly physically evident, over the citizenry and within the framework of the process of transformation of the agrarian traditional city into the contemporary industrial city.

\section{Public space as a place of the ideologies}

In public spaces we meet and we are seen, and in them we carry out the staging of our social origin, as well as expressing our yearnings for transformation [10]. However, we do not have to forget a transcendental event to be able to value the new dimension that the public space has acquired in our time, from the Internet Era, that is to say, the virtual public space [11], and that as we have been able to verify in the Arab Spring, in a transition process, it has a particular importance when agglutinating the ideological arguments that cannot be expressed in the physical public agora due to the greater ease of repression of ideas in the urban space as opposed to the virtual.

We attend to a recombination of the solid variables of the physical public space with the immaterial variables of the virtual space, as Zygmunt Bauman defines 
with his paradigm of "liquid modernity" in which we can recognise the double quality of the flows and the matter and the real nonexistence of the urban emptiness as space without any context, since even the non-places are the ideological expression of a way to make the city.

\subsection{Public space as a structure of ownership}

The present economy of Western Europe is taking giant steps towards outsourcing, as the result of the new division of work and of capital in the globalized era. In Andalusia, this confrontation has occurred in a violent and organised manner since the decade of the sixties of the 20th century. Today, we still find the diagnosis by Lefebvre in 1974 to be valid [12]. In the space, we can read the organising systems of land ownership, and as Lefebvre clarifies for us, we can observe in full detail how the dialectic relationship between dominant space and dominated space behaves, as an expression of the economic forces that make the land their place of investment, and the space their place of amusement.

Thus, in Andalusia, we are found with an accelerated process of production of new spaces, those which we termed in our research project as Emergent Spaces and Spaces in Emergency and which constitute a global model. This trend can be identified in numerous cities and towns all over the planet, whilst they conserve an undoubtedly local stamp. The variable common to most of these experiences is that of a model of horizontal management with a strong root in the World Wide $W e b$, which allows the import of experiences of good practices and the transfer of results, being models where its relationship with the public space predominates. But to whom does the public space belong? We raised this question not in a legal sense of ownership related to the accumulation or disposition of things, but as Jacobs [13] understood it when she spoke of the American city, that is to say, the ownership of the public space associated with the use that the citizenry makes of it, in this case, making street life an indication of urban harmony and quality of life. This is an analysis with which Horacio Capel agrees, when considering the city as a scenario of conflicts and complexities which, therefore, drives us to know the city from a transversal vision [14].

\subsection{Public space as a social construction and urban regenerator}

This last approach on the state of the question in relation to the research, from its episteme or its method, we are going to close with a warning. The previous approaches to the public space: as a history of the community, as a place of ideologies, as a structure of ownership, as a territorial scenario, as a constructed project and as a social construction, they contain important devices of connectivity, since dissecting the public space in some of the previous categories would only lead us to its partial and biased understanding. Thus, we have used this form for the best structuring of the content of the research that we have taken as reference. Although we also have to indicate that those references could be placed, referring to the general work cited for each author, in any other of the sections aimed at analysing the state of the question, given its conceptual and, therefore, relational wealth. However, we also have to conclude by affirming that it is in the 
statement of this last section, where we more precisely reflect the ideological standpoints, the project strategies, the economic considerations and the historical circumstances to which we have previously referred. The main trend that can be drawn is that it is the social subject that really justifies the existence of the public space.

In Andalusia we must make some considerations to redefine the debate around the public space as a social construction, highlighting in this relationship: That the construction of the space forms part of the social process itself, being understood in its historical, political and socioeconomic condition; that the construction of the public space is inseparable from its dimension of ideological, individual or collective expression, as public opinion; that the public space is characterised by its dynamism, being permanently constructed and admitting all types of changes; that the public space, although varying morphologically in each geo-cultural area, is possessor of the constant of social place; that the public space is the result of the operation of rationalising the territory, establishing its physical limits and its uses; that the public space recombines the vectors of time-history and space-nature interactively without establishing primacy for any of them; that the visibility of the whole social body in the public space is what allows the inclusion; and, that it is the wealth and variety of uses that assures the sustainability of the public space.

The history of the present comprehensive urban regeneration, the concept of comprehensive conservation linked to the need for rehabilitation of the architectural heritage, understood beyond the monument as a singular element, arose with the European Charter of the Architectural Heritage, in which it is estimated that the conservation of this heritage depends, to a great extent, on its integration into the framework of the life of the citizens and its consideration in territorial and urban planning. With the Declaration of Amsterdam of 1975, the idea of the building as an exclusive object of conservation was overtaken by the recognition of the need to approach urban rehabilitation at district level, comprehensively, emphasising its social component and avoiding the habitual processes of abandonment, ruin and demolition until the last moment; strengthening reusability as opposed to the new occupations of the land. With the generalised acceptance of the concept of Sustainable Development, disseminated by means of the Brundtland Report [15] of 1987, in the same period in which the ecological footprint of the Earth would be surpassed for the first time, the initiatives to achieve sustainability began at the European and urban level. Sustainability was understood at the environmental, economic and social equality levels, pillars to which governance would later be added as a fundamental element for urban functioning.

\section{Conclusions of Project Andalucía Transversal}

Andalucía Transversal [16] has developed its experience and its contribution to the reality of what is public in the Andalusian city, through an active methodology and the participation of agents and the citizenry. With the objective of optimising resources, a collaborative working model was structured into three groups of 


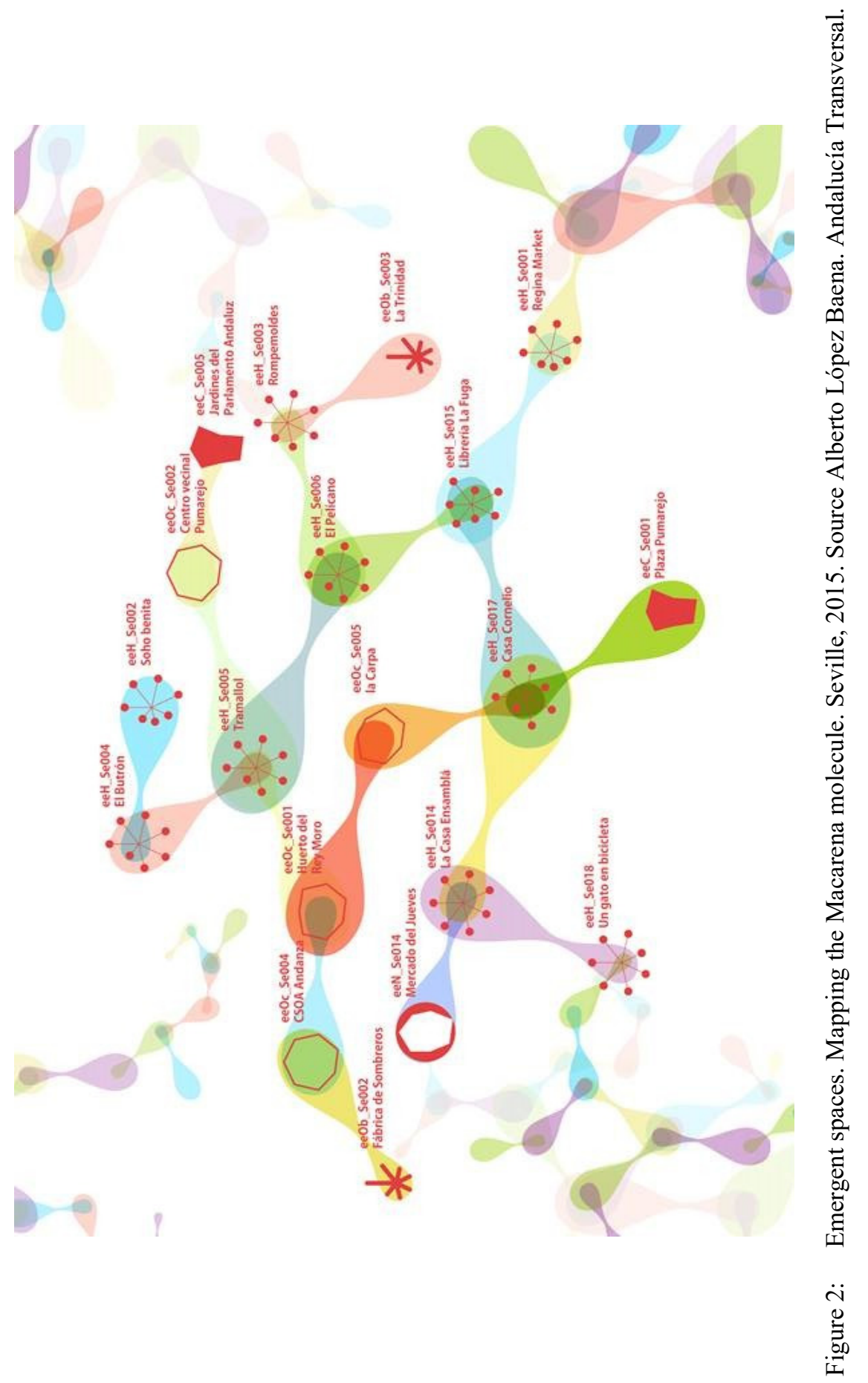


actors: The users, in the broad concept, the citizenry in an individualised manner and the public or private entities; the collaborating people who participated in the collection and entering of data, as well as in the establishment and advising of networks; and, the partners who have taken part directly in the research process. It has been detected that the spheres of intervention are very varied and of a biased diagnosis. The scale of the situations oscillates from the urban fragment to the territorial structures of great standing. Their analysis has allowed testing some assumptions on intervention methods, their contexts and their programmes, and to detect which are the innovative trends. It is understood that the selection of the type of intervention, project or management has been an important and critical element in our research, and that therefore, the who, where and how are decisive. The initial cartographies help to highlight the disconnect existing between the project of public space in Andalusia and the social, urban and territorial reality. Situations are detected of qualitative improvement of the city in large dismantled spaces, ports and industries that do not introduce territorial or economic strategies; micro-policies of urban rehabilitation without integration of public policies; transformations or actions on mobility infrastructures without intermodal connections are observed.

The use of digital platforms of participation, where the citizenry maintains a scenario of interchange between the reality, the projects and the research, supposes an increase of the creative and executive capacities, and a better understanding of the realities in which we work. The methodologic renovation that is set out is accompanied by the development of the new analytical technologies that make it possible to establish synergies between the city and the citizenry. Instruments such as spatial data infrastructures or open code mapping platforms, favour the processes of transversality and the creative production of knowledge. This instrumental force that technology gives us in the study of the public spaces and the city, introduces new scenarios where the urban complexity can be represented, and new mechanisms of governance can be inserted.

\section{Acknowledgements}

The project was funded by the Plan I $+\mathrm{D}+\mathrm{i}$ of the Ministry of Public Works and Housing of the Junta de Andalucía and the European Regional Development Fund of the European Union (FEDER). Project Code: G-GI3001/IDIU.

\section{References}

[1] Choay, F., La terre qui meurt, Fayard: Paris 2001.

[2] Staeheli L. A., Locating the Public in Research and Practice, Progress in Human Geography 31, pp. 792-811, 2007.

[3] Lefevbre, H., Espacio y política. El derecho a la ciudad, Península: Barcelona, pp. 65-68, 1976.

[4] UNESCO: http://whc.unesco.org/document/117660

[5] Foucault, M., Dits et Écrits, Gallimard: Paris, 2001. 
[6] Foucault, M. Des espaces autres, Architecture, Mouvement, Continuité, $\mathrm{n}^{\mathrm{o}} .5$, octubre, 1984.

[7] Lippman, W., The Phantom Public, Transaction Publishers: New Jersey, 1925.

[8] García, A., Utopía y realidad en el microcosmos de los espacios públicos de los conjuntos históricos, IAPH: Seville, 2008.

[9] Sennett R., Carne y piedra: el cuerpo y la ciudad en la civilización occidental. Alianza Editorial: Madrid, 1994.

[10] Borja J. and Muxí Z., El espacio público, ciudad y ciudadanía, Electa: Barcelona, 2003.

[11] Castells, M., Espacios públicos en la sociedad informacional, Urbanitats $n^{\circ}$. 7, Centro de Cultura Contemporánea de Barcelona: Barcelona, 1998.

[12] Lefebvre, H., La producción del espacio, Capitán Swing: Madrid, 2013.

[13] Jacobs, J., Muerte y vida de las grandes ciudades. Península: Madrid, 1967.

[14] Capel, H., La morfología de las ciudades, la sociedad, cultura y paisaje urbano, Ediciones del Serbal: Barcelona, 2002.

[15] Brundtland, G. O; http://www.un-documents.net/our-common-future.pdf

[16] Andalucía Transversal.: http://blog.andaluciatransversal.com 